\title{
A TRANSIÇÃO DOS DISCENTES DA EDUCAÇÃO INFANTIL PARA O Io ANO DO ENSINO FUNDAMENTAL I NUMA ESCOLA MUNICIPAL DE GOIANINHA/RN
}

\author{
THE TRANSITION OF CHILDREN'S EDUCATION DISCOUNTS FOR THE I ${ }^{\circ}$ YEAR OF \\ FUNDAMENTAL EDUCATION IN A MUNICIPAL SCHOOL OF GOIANINHA / RN
}

\author{
Elizângela das Chagas Lemos ${ }^{\mathrm{I}}$ \\ Raquel Cássia Domingues Morato ${ }^{2}$
}

RESUMO: A transição das crianças do nível $\mathrm{V}$ da Educação Infantil para $\mathrm{o} \mathrm{I}^{\circ}$ ano do Ensino Fundamental tem provocado indagações para a educação, principalmente no que tange às políticas públicas e sua adequação às práticas pedagógicas. O objetivo deste artigo é analisar e discutir questões que atravessam essas etapas a partir de pesquisa desenvolvida com alunos do nível $\mathrm{V}$ da Educação Infantil de 2016 até o Io Ano do Ensino Fundamental I em 2017 do turno vespertino numa Escola Municipal do município de Goianinha/RN. Pesquisar as práticas com crianças nestas duas modalidades de ensino permitiu problematizar o trabalho de acompanhamento deles nesse processo de mudança. Mais do que conceber essa mudança de modo dicotômico, trata-se de pensar, para além, das transições e desafios na organização dos sistemas de ensino e em termos de políticas e gestão pública, de propostas curriculares, de formação de professores e de todos os profissionais envolvidos neste trabalho. Com este objetivo, o primeiro item analisa as perspectivas da Base Nacional Comum Curricular (BNCC) que o docente tem acesso para trabalhar com as crianças de 5 a 6 anos. O segundo apresenta a pesquisa no que diz respeito a formação dos professores em destaque. $O$ terceiro sugere prioridades para o trabalho com a leitura e a escrita com o intuito de obter resultados satisfatórios em relação ao avanço do desempenho escolar dos alunos.

Palavras-Chave: Transição, Educação Infantil, Ensino Fundamental.

ABSTRACT: The transition of children from level V of Infant Education to the first year of Elementary School has provoked questions for education, especially regarding public policies and their adequacy to pedagogical practices. The objective of this article is to analyze and discuss issues that cross these stages from research developed with students from level V of Early Childhood Education from 2016 to the ist Year of Elementary School I in 2017 of the afternoon shift at a Municipal School in the city of Goianinha/RN. Researching the practices with children in these two modalities of teaching allowed to problematize the work of accompanying them in this process of change. More than conceiving this change in a dichotomous way, it is a question of thinking, in addition, of transitions and challenges in the organization of education systems and in terms of

\footnotetext{
${ }^{1}$ Graduada em Ciências Biológicas pela Universidade Potiguar (2003) e Pedagogia pela Universidade Potiguar. E-mail: elizangela_cl@yahoo.com.br.

2 Graduação em supervisão e inspeção escolar pela faculdade do meio ambiente e tecnologia de negócio, Brasil(2012). Coordenadora Pedagógica do Secretaria de Educação de Goianinha, Brasil.
} 
policies and public management, of curricular proposals and of teacher training and of all professionals involved in this work. With this aim, the first item analyzes the perspectives of the National Curricular Common Base (BNCC) that the teacher has access to work with children from 5 to 6 years. The second presents the research regarding the training of the teachers in the spotlight. The third suggests priorities for working with reading and writing in order to obtain satisfactory results in relation to the progress of students' school performance.

Keywords: Transition, Child Education, Elementary Education.

\section{INTRODUÇÃO}

Sabemos que Educação Infantil consiste no desenvolvimento de um trabalho na formação de crianças, cujo objetivo é que elas se tornem aptas para viver numa sociedade democrática, multidiversificada e em constante mudança.

Esse período é um importante recurso de apoio ao aluno, desenvolvendo assim o contato sistemático com outras crianças, aprendendo a partilhar, trocar, conviver com regras e em equipe, a brincar, dividir e trabalhar. Desta forma, o discente alarga as suas habilidades e as suas competências necessárias para o devido segmento de estudo; entretanto, a criança constrói um repertório adequado para enfrentar os desafios do ensino fundamental. A promoção à pré-escola é fundamental para o desenvolvimento cognitivo e psicossocial nos primeiros anos da educação infantil. Com essas áreas desenvolvidas, a criança do ensino infantil com migração para o ensino fundamental depara com extensa agenda de novas habilidades, competências, conhecimentos adquiridos e desenvolvidos.

[...] Desenvolvimento em cada ciclo de vida, esse momento que pode ser considerado uma transição de vida para um novo estágio, com suas tarefas específicas, que desencadeiam um processo de transição qualitativa de competências para lidar com novas exigências. (MARTURANO, E. et al, 2009, p. 93).

As trocas que as crianças fazem com o meio social, sejam na escola, no ambiente familiar e nas brincadeiras com os amigos implicam no manejo de situações simbólicas e conceituais, com isto desenvolvendo a aprendizagem. Que é um processo pelo qual os nossos conhecimentos, habilidades e competências são adquiridos ou modificados, desde o nascimento até a fase adulta. A aprendizagem significativa valoriza a compreensão da valorização, o querer aprender do sujeito

espontaneamente. É o reconhecimento de dinâmicas que envolvem o ensino, é a relação de conhecimento que o indivíduo já possui, com o novo conhecimento.

Aprendizagem consiste em codificação e decodificação, aquisição de uma técnica numa estreita relação entre emissor e receptor. Deve-se considerar também o conhecimento cultural que se dá através deste processo, isto é, da interação, do habitus, do campo e do diálogo. Esse capital 
cultural influência a forma de relação entre o nível cultural global da família e o êxito escolar da criança.

$\mathrm{Na}$ realidade, cada família transmite a seus filhos, mais por vias indiretas que diretas, um certo capital cultural e um certo ethos, sistema de valores implícitos e profundamente interiorizados, que contribui para definir entre coisas, as atitudes face ao capital cultural e a instituição escolar. (NOGUEIRA; CATANI, 2007, p.4I).

O Io Ano do Ensino Fundamental é um período de incertezas e imprevisibilidades, no qual, as crianças serão mobilizadas por um contexto mais complexo do que o ensino infantil, seus medos, suas emoções, ansiedades e excitações; estarão mais acentuados neste período de adaptação no processo de transição. É uma combinação das novas demandas com expectativas de autonomia em um ambiente físico, social e cognitivo.

Segundo Bourdieu (NOGUEIRA; CATANI, 2007), o contexto escolar não cobra dos alunos apenas o que foi ensinado, ele acaba cobrando também outras habilidades que são fáceis para uns e estranhos para outros, assim ele acaba enfatizando as diferenças. Os alunos que cresceram em culturas distintas ou que não possuem um bom Capital da Cultura dominante se enganam e pensam que a dificuldade é a falta de inteligência.

Para que sejam desfavorecidos os mais favorecidos, é necessário e suficiente que a escola ignore, no âmbito dos conteúdos do ensino que transmite, dos métodos e técnicas de transmissão e dos critérios de avaliação, as desigualdades culturais entre as crianças das diferentes classes sociais. Tratando todos os educandos, por mais desiguais que sejam eles de fato, como iguais em direitos e deveres, o sistema escolar é levado a dar sua sanção às desigualdades iniciais diante da cultura”. (NOGUEIRA; CATANI, 2007, p. 53).

A relevância em desenvolver esse tema, justifica-se por considerarmos que o mesmo traz controvérsias para o processo de ensino/aprendizagem do aluno que passa pela transição do Nível $\mathrm{V}$ da Educação Infantil ao Io ano do Ensino Fundamental. $\mathrm{O}$ interesse em pesquisar e investigar questões relativas as consequências da falta de adaptação dos alunos no período dessa mudança surgiram a partir das queixas dos docentes e de um levantamento feito por eles a partir das causas mais frequentes das dificuldades encontradas nesta ação.

Nessa esfera, procuramos identificar como a qualificação dos professores dos referidos níveis influenciam nas consequências desse período de transição. Além disso, fizemos um levantamento 
do plano de ensino Municipal junto a prática pedagógica docente, para caracterizar os conhecimentos adquiridos pelo aluno no processo de ensino e aprendizagem.

[...] o processo de adaptação deve ser planejado pelas instituições a fim de promover a qualidade no atendimento bem como não causar demasiado estresse para os envolvidos, o que pode deixar marcas a curto e logo prazo e interferir no processo de ensino/aprendizagem. (RAPOPORT, A. et al, 2008, p. 269).

Observou-se que algumas crianças vêm mostrando dificuldades em um repertório prévio para lidar com os desafios do $\mathrm{I}^{0}$ ano do Ensino Fundamental, com isto, se faz necessário fazer um levantamento do plano de ensino municipal junto a prática pedagógica docente, mudando a óptica do contexto atual das escolas, reconstruindo diariamente o seu processo de ensino/aprendizagem do Nível V da Educação Infantil ao ${ }^{0}$ ano do Ensino Fundamental.

Em suma, trata-se de um acompanhamento do desenvolvimento dos alunos sob o olhar do docente, respaldados sobre uma matriz curricular, do alunado do nível V da Educação Infantil de 2016 até o Io Ano do Ensino Fundamental em 2017 do turno vespertino numa Escola Municipal do Município de Goianinha/RN.

\section{Revisão Bibliográfica}

A revisão bibliográfica para esta pesquisa será constituída, inicialmente, por autores que analisam e discutem questões sobre a transição do nível $\mathrm{V}$ da Educação Infantil ao $\mathrm{I}^{\circ}$ ano do Ensino Fundamental I, bem como a influência da prática pedagógica docente respaldada por um plano de ensino Municipal, além de fazer um levantamento dos critérios para o ingresso das crianças no ano inicial do Ensino Fundamental por parte do docente e como sua formação influenciará nessa ação. Tais questões se revelam como base para a abordagem a se realizar.

Nessa perspectiva, a contribuição de autores como Marturano (2009) e Rapoport (2008) tornam-se fundamentais, pois trazem luz para entender questões e consequências das novas esferas em relação a transição da Educação Infantil para os anos iniciais do Ensino Fundamental que deixam marcas profundas nas crianças, mudando assim seu comportamento.

Bourdieu (2007), Nogueira e Catani (2007) enaltecem sobre o capital cultural das crianças que são transmitas pela família, por mais vias indiretas que diretas, o que nos permite entender, que 
o alunado deve ser tratado como iguais em direitos e deveres, e que o sistema escolar é levado a dar sua sanção às desigualdades iniciais diante da diversidade cultural de cada um.

Emilia Ferreiro e Anna Teberosky (1986) irão contribuir através dos estudos da psicogênese da língua escrita, pelo qual o alunado será avaliado de acordo com suas habilidades e competências.

Assim, também se faz necessário utilizar a Base Nacional Comum Curricular de 2018 (BNCC), no qual o docente tem acesso para trabalhar com seu público-alvo. Destacando os procedimentos metodológicos e avaliativos utilizados para obtenção dos resultados em relação ao avanço do desempenho escolar do alunado.

Pino (1996), por sua vez, conceitua o processo educacional pelo qual, o indivíduo internaliza a cultura que é submetida a partir da mediação social. Com isto, fazendo um paralelo entre o desenvolvimento humano e a educação, dois aspectos de uma mesma face.

Vygotsky (1994) sinaliza, então, a perspectiva de análise do desenvolvimento de um indivíduo que se dá através de uma um complexo processo dialético. No qual, o brinquedo, objeto utilizado principalmente na Educação Infantil, dirige o desenvolvimento da criança.

Em suma, os conceitos e seus respectivos autores concretizam significativas contribuições para os objetivos que se espera alcançar com esta pesquisa.

\section{Metodologia}

O debuxo metodológico escolhido para as devidas justaposições do presente artigo serão de investigação que congregue o uso de técnicas qualitativas que serão realizadas numa escola municipal da Zona Rural da microrregião II do Município de Goianinha no turno vespertino. No estudo a ser realizado, quanto à abordagem do problema, de cunho qualitativo foi definido por considerar que há uma relação dinâmica entre o mundo objetivo e concreto, e a subjetividade do sujeito/aluno que não será refletida através de números.

Pode-se definir método como caminho para se chegar a determinado fim. E método científico como o conjunto de procedimentos intelectuais e técnicos adotados para se atingir o conhecimento. (GIL, 2008 p. 28).

A pesquisa de acordo com os objetivos determinados será descritiva-exploratória. No âmbito descritivo se dará pela necessidade de registrar e descrever os acontecimentos no transcorrer do processo de ensino-aprendizagem abordadas pelos docentes do Nível V (Educação infantil) e ${ }^{\circ}$ ano (Ensino Fundamental I), a fim de referir características do nível de aprendizagem desenvolvida por Emília Ferreiro de forma padronizada de coleta de dados. Optou-se também como um dos 
instrumentos e procedimentos a serem utilizados no campo da presente pesquisa, a realização de questionário (Apêndice A) com os professores do Nível V da Educação Infantil e do $\mathrm{I}^{\mathrm{0}}$ ano do Ensino Fundamental. O questionário será semi-aberto, desenvolvido com base em um roteiro básico, previamente elaborado, com perguntas abertas e fechadas, para a construção dos dados de análise. E será exploratória, pois busca levantar e definir mais informações sobre o assunto, para delimitar o tema de pesquisa, definir objetivos, levantar hipóteses e é claro fazer descobertas sobre o assunto em questão. (PRODANOV, 2013).

Teremos como base de analise também o relatório relacionado ao aluno desenvolvido pelos docentes que descrevem com precisão as habilidades e competências do alunado. Compreendendo assim, a evolução do mesmo durante sua transição do Nível $V$ da Educação Infantil ate ao $\mathrm{I}^{\circ}$ do ensino fundamental I.

Dessa forma, os conceitos e seus respectivos autores trazem efetiva contribuição para os objetivos que se espera alcançar com esta pesquisa.

\section{Resultados e discussões}

Este estudo se baseia na premissa de caracterizar os conhecimentos adquiridos pelo discente durante sua transição do Nível V da Educação Infantil para o $\mathrm{I}^{\mathrm{o}}$ ano do Ensino Fundamental, bem como a metodologia aplicada pelos docentes para que os mesmos possam avançar nos níveis de aprendizagem, segundo pressupostos de Emilia Ferreiro.

Em relação ao primeiro objetivo, está respaldado sob a perspectiva da Base Nacional Comum Curricular que o docente tem acesso para alavancar resultados positivos do discente.

Em relação ao nível V da Educação Indantil, o município possui a matriz curricular, mas não é disponibilizado ao professor, tendo em vista que o mesmo necessita para direcionar suas atividades. Sendo assim, a escola faz uso do material disponibilizado pelo site do Ministério da Educação (MEC).

Já em relação a matriz curricular do Ensino Fundamental I, o município não o possui, porém assim como o da Educação Infantil a escola aderiu ao material do MEC, como uma referência mínima. Não sendo uma regra, tendo a desqualificar o padrão de habilidades e competências de seus discentes. Conforme não possuímos essa referência no município, o trabalho pedagógico perde uma característica própria.

O segundo objetivo explorado foi investigar a formação dos professores em destaque: A professora do Nível V da Educação Infantil, é especialista em Educação Infantil e encontra-se em processo de qualificação no curso de especialização em Fundamentos Linguísticos para o Ensino da 
Leitura e da Escrita pela Universidade Federal do Rio Grande do Norte (UFRN); já a professora do $\mathrm{I}^{\mathrm{o}}$ ano do Ensino Fundamental participa do curso de formação do Pacto de Alfabetização na Idade Certa (PNAIC) oferecida pelo governo federal, e também é Especialização em Educação Ambiental e Geografia do Semiárido: uma abordagem interdisciplinar pelo Instituto Federal do Rio Grande do Norte (IFRN).

A esse respeito, constatou-se que esses docentes envolvidos nesse estudo apresentam a qualificação necessária para desempenhar o processo de alfabetização adequado ao alunado. Assim, dando continuidade no processo educacional do Ensino Infantil para o Ensino Fundamental.

O terceiro objetivo, foi investigar os resultados em relação ao avanço do desempenho escolar dos alunos, levando em consideração os pressupostos de Ferreiro (1986, p.182), que ressalta que a evolução da escrita passa por três níveis, pré-silábico (PS), silábico (S) e alfabético (A). Para preservar o público-alvo desta pesquisa, designamos por números:

Tabela I - Níveis de aprendizagem dos alunos de Nível V da Educação Infantil da Escola Municipal no ano de 2016

\begin{tabular}{|c|c|c|c|c|c|c|c|c|c|}
\hline \multirow{2}{*}{$\begin{array}{c}\text { Alunos } \\
\mathbf{2 0 1 6}\end{array}$} & \multicolumn{2}{|c|}{$\mathbf{1}^{\circ}$ semestre } & \multicolumn{3}{c|}{$\mathbf{2}^{\mathbf{0}}$ semestre } & \multicolumn{3}{c|}{ Culminância } \\
\hline & $\mathrm{PS}$ & $\mathrm{S}$ & $\mathrm{A}$ & $\mathrm{PS}$ & $\mathrm{S}$ & $\mathrm{A}$ & $\mathrm{PS}$ & $\mathrm{S}$ & $\mathrm{A}$ \\
\hline $\mathrm{I}$ & $\mathrm{X}$ & & & $\mathrm{X}$ & & & & $\mathrm{X}$ & \\
\hline 2 & $\mathrm{X}$ & & & $\mathrm{X}$ & & & & $\mathrm{X}$ & \\
\hline 3 & $\mathrm{X}$ & & & $\mathrm{X}$ & & & $\mathrm{X}$ & & \\
\hline 4 & $\mathrm{X}$ & & & $\mathrm{X}$ & & & $\mathrm{X}$ & & \\
\hline 5 & $\mathrm{X}$ & & & $\mathrm{X}$ & & & $\mathrm{X}$ & & \\
\hline 6 & $\mathrm{X}$ & & & $\mathrm{X}$ & & & $\mathrm{X}$ & & \\
\hline 7 & $\mathrm{X}$ & & & $\mathrm{X}$ & & & $\mathrm{X}$ & & \\
\hline 8 & $\mathrm{X}$ & & & $\mathrm{X}$ & & & $\mathrm{X}$ & & \\
\hline 9 & $\mathrm{X}$ & & & $\mathrm{X}$ & & & $\mathrm{X}$ & & \\
\hline $\mathrm{IO}$ & $\mathrm{X}$ & & & $\mathrm{X}$ & & & & $\mathrm{X}$ & \\
\hline $\mathrm{II}$ & $\mathrm{X}$ & & & $\mathrm{X}$ & & & & $\mathrm{X}$ & \\
\hline $\mathrm{I} 2$ & $\mathrm{X}$ & & & $\mathrm{X}$ & & & $\mathrm{X}$ & & \\
\hline $\mathrm{I} 3$ & $\mathrm{X}$ & & & $\mathrm{X}$ & & & & $\mathrm{X}$ & \\
\hline $\mathrm{I} 4$ & $\mathrm{X}$ & & & $\mathrm{X}$ & & & $\mathrm{X}$ & & \\
\hline $\mathrm{I} 5$ & $\mathrm{X}$ & & & $\mathrm{X}$ & & & & $\mathrm{X}$ & \\
\hline $\mathrm{I} 6$ & $\mathrm{X}$ & & & $\mathrm{X}$ & & & $\mathrm{X}$ & & \\
\hline
\end{tabular}

Tabela 2 - Níveis de aprendizagem dos alunos do $\mathrm{I}^{\circ}$ ano do Ensino Fundamental da Escola Municipal no ano de 2017

\begin{tabular}{|c|c|c|c|c|c|c|c|c|c|}
\hline \multirow{2}{*}{$\begin{array}{c}\text { Alunos } \\
2017\end{array}$} & \multicolumn{3}{|c|}{$\mathbf{1}^{\circ}$ semestre } & \multicolumn{3}{c|}{$\mathbf{2}^{\circ}$ semestre } & \multicolumn{3}{c|}{ Culminância } \\
\cline { 2 - 8 } & PS & S & A & PS & S & A & PS & S & A \\
\hline
\end{tabular}




\begin{tabular}{|c|c|c|c|c|c|c|c|c|c|}
\hline $\mathrm{I}$ & & $\mathrm{X}$ & & & $\mathrm{X}$ & & & & $\mathrm{X}$ \\
\hline 2 & & $\mathrm{X}$ & & & $\mathrm{X}$ & & & & $\mathrm{X}$ \\
\hline 3 & $\mathrm{X}$ & & & $\mathrm{X}$ & & & & $\mathrm{X}$ & \\
\hline 4 & $\mathrm{X}$ & & & $\mathrm{X}$ & & & & $\mathrm{X}$ & \\
\hline 5 & $\mathrm{X}$ & & & $\mathrm{X}$ & & & & & $\mathrm{X}$ \\
\hline 6 & $\mathrm{X}$ & & & $\mathrm{X}$ & & & & & $\mathrm{X}$ \\
\hline 7 & $\mathrm{X}$ & & & $\mathrm{X}$ & & & & $\mathrm{X}$ & \\
\hline 8 & $\mathrm{X}$ & & & $\mathrm{X}$ & & & & $\mathrm{X}$ & \\
\hline 9 & $\mathrm{X}$ & & & $\mathrm{X}$ & & & & $\mathrm{X}$ & \\
\hline $\mathrm{IO}$ & & $\mathrm{X}$ & & & $\mathrm{X}$ & & & & $\mathrm{X}$ \\
\hline $\mathrm{II}$ & & $\mathrm{X}$ & & & $\mathrm{X}$ & & & $\mathrm{X}$ & \\
\hline $\mathrm{I} 2$ & $\mathrm{X}$ & & & $\mathrm{X}$ & & & & $\mathrm{X}$ & \\
\hline $\mathrm{I} 3$ & & $\mathrm{X}$ & & & $\mathrm{X}$ & & & & $\mathrm{X}$ \\
\hline $\mathrm{I} 4$ & $\mathrm{X}$ & & & $\mathrm{X}$ & & & & $\mathrm{X}$ & \\
\hline $\mathrm{I} 5$ & & $\mathrm{X}$ & & & $\mathrm{X}$ & & & $\mathrm{X}$ & \\
\hline $\mathrm{I} 6$ & $\mathrm{X}$ & & & $\mathrm{X}$ & & & & $\mathrm{X}$ & \\
\hline
\end{tabular}

Esse resultado satisfatório, reflete sobre o uso de estratégias por parte do docente que auxiliam no confronto e avanços das hipóteses da escrita dos alunos. Desde o uso de alfabeto móvel, caça-palavras, cruzadinhas, jogos de memória etc. A sensibilidade do mestre tem uma forte influência na qualidade do ensino, pois com o domínio de estratégias adequadas respeitando esses níveis, acabam por melhorar o desempenho da criança.

As atividades utilizadas pelos docentes com o público-alvo foram ricas em recursos simbólicos e exploratórios a fim de acentuar a curiosidade infantil na busca constante pelo conhecimento científico, algo que ocorrerá gradualmente ao longo do seu processo de ensinoaprendizagem.

Em suma, procurou-se neste artigo avaliar o processo de desenvolvimento dos alunos do nível V da Educação Infantil para o $\mathrm{I}^{\mathrm{o}}$ ano do Ensino Fundamental, bem como a metodologia aplicada pelos docentes para que os mesmos possam avançar nos níveis de aprendizagem, segundo pressupostos de Emilia Ferreiro.

\section{Considerações finais}

Buscando refletir sobre os conhecimentos adquiridos pelo alunado durante o processo de transição da última etapa da educação infantil para o primeiro ano do ensino fundamental do turno vespertino da Escola Municipal Alberto Torres Galvão entre os anos de 2016 a IoI7, compreendemos que por meio das análises que este processo atendeu de forma satisfatória as orientações presentes no documento do MEC, a Base Nacional Comum Curricular (BNCC). 
A afetividade, a compreensão e a flexibilidade devem ser demonstradas pelos professores, especialmente neste momento de transição pelo qual o aluno passa ao sair da Educação Infantil e se aventurar pelo Ensino Fundamental. É de suma importância que a Instituição de Ensino esteja preparada para este momento de adaptação. Para tanto, a ligação com a família é de grande valia, pois juntos, escola e família, poderão identificar possíveis problemas e assim solucioná-los ou até mesmo amenizá-los. E é claro, quando necessário encaminhá-los para um atendimento especializado.

Enfim, podemos concluir que ainda há muito o quer ser feito para que a transição da educação infantil para o ensino fundamental ocorra de maneira que se priorizem as necessidades das crianças e o processo de ensino aprendizagem e desenvolvimento.

\section{Referências}

AUSUBEL, D. P. A aprendizagem significativa: a teoria de David Ausubel. São Paulo: Moraes, 1982.

Base Nacional Comum Curricular (BNCC). Acesso em: 03/05/2018. Disponível em: 〈http://basenacionalcomum.mec.gov.br/images/BNCC_publicacao.pdf〉.

BOURDIEU, P. Capital Cultural, Escuela y Espacio Social. México: Siglo Veinteuno, 1997.

BOURDIEU, P. Questões de Sociologia. Rio de Janeiro: Marco Zero, 1983.

CRUZ, M. N. Educação infantil e ampliação da obrigatoriedade escolar: implicações para o desenvolvimento cultural da criança. acesso em: 03/06/2018. disponível em: $\langle$ www.scielo.br/pdf/ccedes/v37nio2/1678-7110-ccedes-37-102-00259.pdf $\rangle$.

FERREIRO, Emília e TEBEROSKY, Ana. Psicogênese da Língua Escrita. Porto Alegre: Art Med, 1986.

GIL, Antônio Carlos. Métodos e técnicas de pesquisa social. 6ํㅡㄹ ed. Atlas, São Paulo: 2008.

MARTURANO, E.; FERREIRA, M.; GARDINAL, E. Estresse Cotidiano na Transição da à Série: Percepção dos Alunos e Associação com Desempenho e Ajustamento. Psicologia: Reflexão e Crítica, v. 22, n.I, p. 93-I0I, 2009.

NOGUEIRA, M.A.; CATANI, A.M. Uma sociologia da produção do mundo cultural e escolar. In: Bourdieu, P. Escritos de educação. ro. ed. Petrópolis: Vozes, 2008. p. 7-15.

OLIVEIRA, V. M. Transição da Educação Infantil para o Ensino Fundamental. Acesso em: 03/06/2018. Disponível em: $\langle$ «ww.ri.unir.br/jspui/bitstream/123456789/1872/I/OLIVEIRA\%2C\%2oV.\%20M..pdf〉

PINO, A. A psicologia concreta de Vigotski: implicações para a Educação. In: Psicologia da Educação: Revista do Programa de Estudos Pós-Graduados em Psicologia da Educação. Pontificia Universidade Católica de São Paulo. no 7/8 - São Paulo: EDUC, 1996. 
PIZATO, Elaine Cristina Gardinal; MARTURANO, Edna Maria; FONTAINE, Anne Marie Germaine Victorine. Trajetórias de habilidades sociais e problemas de comportamento no ensino fundamental: influência da educação infantil. Psicologia: Reflexão e Crítica, [s.1.], v. 27, n. I, p.189197, mar. 2014. FapUNIFESP (SciELO). http://dx.doi.org/10.1590/so102-7972201400o100o2I.

PRODANOV, Cleber Cristiano. Metodologia do trabalho científico [recurso eletrônico] : métodos e técnicas da pesquisa e do trabalho acadêmico / Cleber Cristiano Prodanov, Ernani Cesar de Freitas. - 2. ed. - Novo Hamburgo: Feevale, 2013.

RAPOPORT, A.; SARMENTO, D.; NORNBERG, M.; PACHECO, S. Adaptação de crianças ao primeiro ano do Ensino Fundamental. Educação. Porto Alegre, v. 31, n. 3, p. 268-273, set/dez, 2008.

VYGOTSKY, L.S. Formação social da mente. São Paulo: Martins Fontes, 199 